\title{
A Rare Case of Aggressive Melanotic Schwannoma Occurred in Spinal Nerve of a 59-Year-Old Male
}

\author{
Sung-eun Choi* . Yoon Jin Cha* \\ Jisup Kim · Hyunseo Cha \\ Jayeong Seo · Sung-Uk Kuh ${ }^{1}$ \\ Sung-Jun $\mathrm{Kim}^{2}$. Se Hoon $\mathrm{Kim}^{3}$ \\ Departments of Pathology, ${ }^{1}$ Neurosurgery, and \\ ${ }^{2}$ Radiology, Gangnam Severance Hospital, \\ Yonsei University College of Medicine, Seoul; \\ ${ }^{3}$ Department of Pathology, Severance Hospital, \\ Yonsei University College of Medicine, Seoul, \\ Korea \\ Received: October 17, 2016 \\ Revised: December 6, 2016 \\ Accepted: January 4, 2017 \\ Corresponding Author \\ Se Hoon Kim, MD \\ Department of Pathology, Severance Hospital, \\ Yonsei University College of Medicine, 50-1 \\ Yonsei-ro, Seodaemun-gu, Seoul 03722, Korea \\ Tel: +82-2-2228-1764 \\ Fax: +82-2-362-0860 \\ E-mail: paxco@yuhs.ac \\ *Sung-eun Choi and Yoon Jin Cha contributed \\ equally to this work.
}

\begin{abstract}
Melanotic schwannoma (MS) is a rare variant of nerve sheath neoplasm that shows ultrastructura and immunophenotypical features of Schwann cells but also has cytoplasmic melanosomes and is reactive for melanocytic markers as well. Unlike conventional schwannoma, which is totally benign, MS has an unpredictable prognosis and is thought to have low-malignant potential. Herein, we present a rare case of recurrent MS in lumbar spine of a 59-year-old male.
\end{abstract}

Key Words: Melanotic schwannoma; Spine; Recurrence; Metastasis
Melanotic schwannoma (MS) is a rare, distinctive tumor which is categorized as a variant of schwannoma. Approximately $50 \%$ of MS have psammomatous calcifications, which is related to Carney complex, an autosomal dominant disorder. ${ }^{1}$ Tumor cells of MS are thought to be Schwann cells that characteristically have melanosomes and are immunophenotypically reactive for melanocytic markers. ${ }^{2}$ We report a case of MS that had occurred in lumbar spinal nerve of a 59-year-old male, which locally recurred 5 years after the surgical removal of the primary tumor and also metastasized to the lung.

\section{CASE REPORT}

This study was approved by the Institutional Review Board of Gangnam Severance Hospital with a waiver of informed consent (IRB No. 3-2016-0255).
A 59-year-old male presented with right buttock pain and radiating leg pain. He had a medical history of hypertension on medication for 10 years. Five years ago, he had a hemi-laminectomy with removal of a spinal cord mass of left L4 level, at the outside hospital, and the diagnosis was MS. On spinal magnetic resonance imaging, tumor in previous operative site, L4 level of spinal cord, was recognized with involvement of L4 vertebral body (Fig. 1A). Tumor recurrence was considered based on the patient's history. Subsequent positron emission tomographycomputed tomography revealed strong fluorodeoxyglucose (FDG) uptake in the L4/5 level. Multiple lung nodules with increased FDG uptake were found in the left upper lobe, right middle lobe, and right lower lobe, which appeared to be consistent with metastatic nodules (Fig. 1B). Patient received total laminectomy of L4 and subtotal laminectomy of L3 lower and L5 upper bodies. The resected specimen submitted in fresh 
state consisted of a product of $\mathrm{L} 4$ corpectomy, including a body of L4 spinal bone and separately sent soft tissue. A 3.3 $\times 2.2-\mathrm{cm}-$ sized black, soft mass was located in the posterior side of the L4 body. On cut section, the black mass was infiltrating into the bone (Fig. 2A).

On histological examination, a cellular pigmented mass was infiltrating the bone marrow (Fig. 2B). Discohesive tumor cells were arranged in solid sheets or nests. Tumor cells had eosino- philic ample cytoplasm, long cytoplasmic process with fuzzy cell borders, and variable amounts of cytoplasmic melanin pigments. Nuclear pleomorphism and prominent macronucleoli were observed with a few mitoses up to 2/10 high power fields (HPFs) (Fig. 2C). Foci of tumor necrosis were observed (Fig. 2D). Immunohistochemical staining for human melanoma black 45 (HMB45; 1:100, clone HMB45, Dako, Carpinteria, CA, USA), S-100 protein (1:2,000, clone bBS/NC/VI-H14, Dako), Ki-67
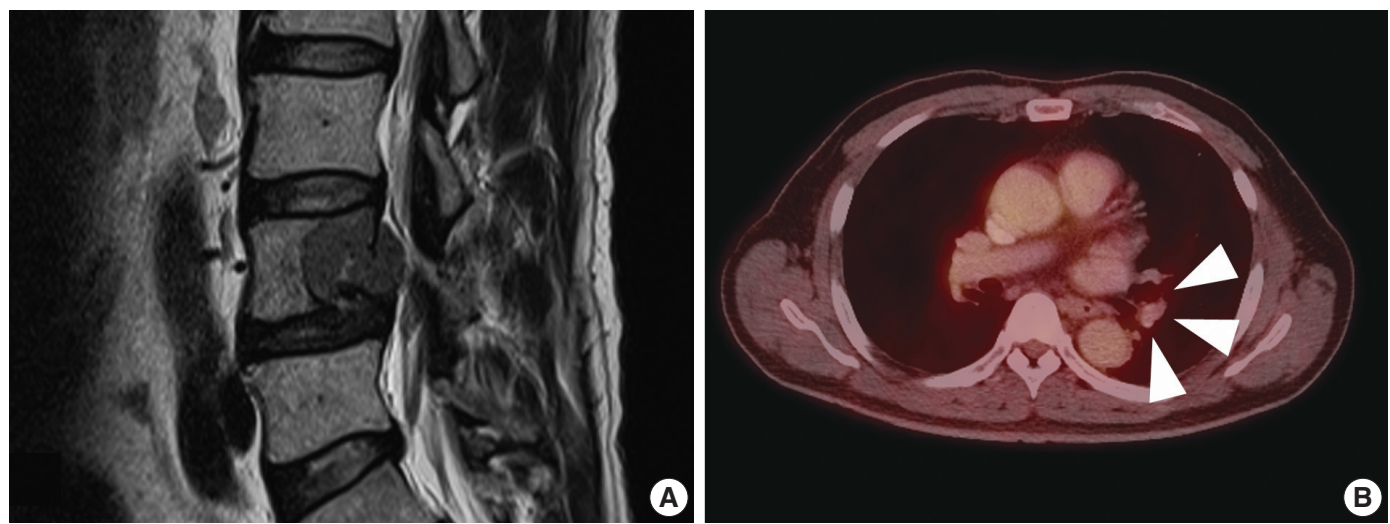

Fig. 1. Radiologic findings of spinal melanotic schwannoma. (A) Magnetic resonance imaging of lumbar spine reveals a destructive mass of the vertebral body. (B) Metastatic pulmonary nodule in left upper lobe with increased fluorodeoxyglucose uptake on positron emission tomography-computed tomography (arrowheads).
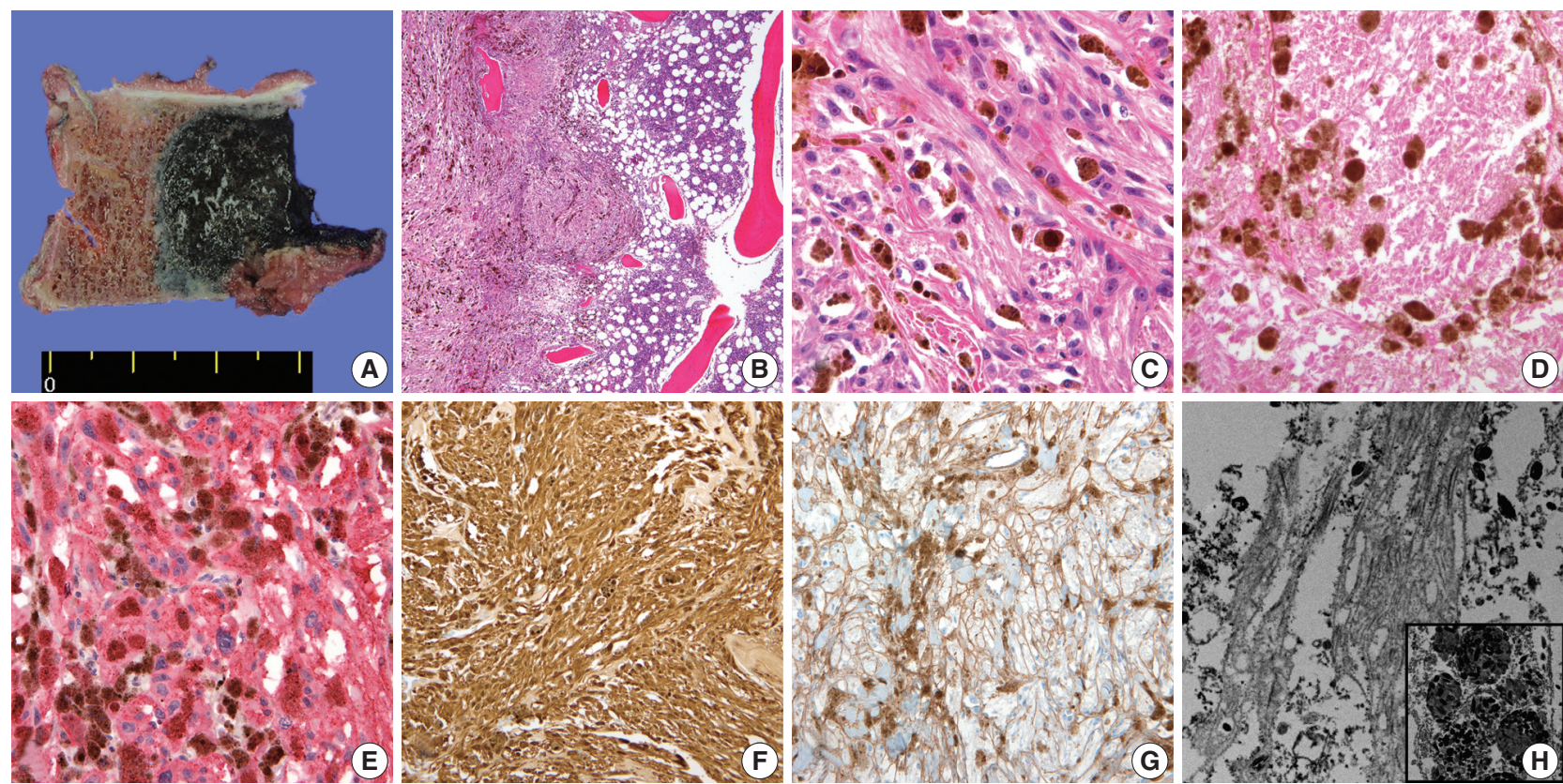

Fig. 2. Gross, microscopic and ultrastructural findings of melanotic schwannoma. (A) A heavily pigmented black round mass of vertebral body has infiltrative margin. (B) Tumor cells permeate the bone marrow space of vertebra (left). Note the right sided normal bone marrow that shows retained trabecular bone and marrow space containing hematopoietic cells. (C) Epithelioid tumor cells have discernible cytoplasmic membrane, pleomorphic nuclei, and cytoplasmic melanin pigments. Note the mitosis (center) and prominent nucleolus. (D) Foci of tumor necrosis are seen. Human melanoma black 45 (E) and S-100 protein (F) are diffusely and strongly positive in tumor cells. (G) Collagen type IV staining reveals pericellular membranous staining of tumor cells, implying the presence of basal lamina. (H) On electron microscopy, abundant basal lamina of tumor cell is evident with cytoplasmic melanosomes $(\times 12,000)$ (inset, $\times 5,000)$. 
Table 1. Previously reported melanotic schwannomas with metastasis

\begin{tabular}{|c|c|c|c|c|c|}
\hline Case No. & Sex & Age (yr) & Primary site & Metastasis site & References \\
\hline 1 & $\mathrm{M}$ & 27 & Bronchus & Brain & Rowlands et al. ${ }^{15}$ (1987) \\
\hline 2 & $\mathrm{~F}$ & 48 & T9-T10 & Lung, skin & Killeen et al. ${ }^{16}(1988)$ \\
\hline 3 & M & 27 & L5 & Lung, pleura & Vallat-Decouvelaere et al. ${ }^{7}$ (1999) \\
\hline 4 & $\mathrm{~F}$ & 35 & L3-L5 & Bone, lymph node & Vallat-Decouvelaere et al. ${ }^{7}$ (1999) \\
\hline 5 & $\mathrm{~F}$ & 45 & T6 & Lung, bone, liver & Vallat-Decouvelaere et al..$^{7}$ (1999) \\
\hline 6 & M & 35 & C4-C5 & Leptomeninges & Santaguida et al..$^{10}(2004)$ \\
\hline 7 & M & 61 & $\mathrm{~T} 7$ & Leptomeninges & Tawk et al..$^{11}(2005)$ \\
\hline 8 & M & 33 & L5-S1 & Lung & Shields et al. ${ }^{12}$ (2011) \\
\hline 9 & $\mathrm{~F}$ & 32 & C4-C5 & Lung & Faria et al. ${ }^{13}(2013)$ \\
\hline 10 & $\mathrm{~F}$ & 15 & Cervical paraspinal & Leptomeninges, parascapular, and neck soft tissues & Torres-Mora et al. ${ }^{8}$ (2014) \\
\hline 11 & $\mathrm{~F}$ & 23 & L4 & Liver & Torres-Mora et al. ${ }^{8}$ (2014) \\
\hline 12 & $\mathrm{~F}$ & 25 & Sacrum & Lung, pleura, lymph nodes & Torres-Mora et al. ${ }^{8}$ (2014) \\
\hline 13 & M & 27 & L2-L3 & Lung, lymph nodes, abdomen & Torres-Mora et al..$^{8}$ (2014) \\
\hline 14 & M & 32 & C2 nerve root & Lung, skeleton & Torres-Mora et al..$^{8}$ (2014) \\
\hline 15 & M & 40 & Paraspinal L3-L4 & Spine (T12) & Torres-Mora et al..$^{8}$ (2014) \\
\hline 16 & $\mathrm{~F}$ & 44 & T5-6 & Lung, posterior chest wall & Torres-Mora et al. ${ }^{8}$ (2014) \\
\hline 17 & M & 47 & L3-L4 & Lung, liver, pleura, leptomeninges, bone & Torres-Mora et al..$^{8}$ (2014) \\
\hline 18 & M & 47 & C5 & Lumbar/thoracic, brain & Torres-Mora et al..$^{8}$ (2014) \\
\hline 19 & M & 61 & T6-T8 & Spinal cord & Torres-Mora et al. ${ }^{8}$ (2014) \\
\hline 20 & $\mathrm{~F}$ & 67 & $\mathrm{~T} 10$ & Liver & Torres-Mora et al. ${ }^{8}$ (2014) \\
\hline 21 & M & 46 & L3 & Brain, leptomeninges & Khoo et al. ${ }^{14}(2016)$ \\
\hline
\end{tabular}

M, male; F, female; T, thoracic spine; L lumbar spine; C, cervical spine.

(1:150, clone MIB-1, Dako), and collagen type IV (1:100, clone CIV 22, Dako) was performed. Tumor cells showed diffuse and strong expression of HMB 45 and S-100 protein (Fig. 2E, F). Collagen type IV was expressed along the pericellular membrane (Fig. 2G). Ki-67 was positive in approximately $1 \%$ of the tumor cells. Under electron microscopy, abundant basal lamina (Fig. 2H) was observed along with the cytoplasmic melanosomes (Fig. 2H, inset).

\section{DISCUSSION}

We reported a rare case of spinal MS that showed local recurrence and pulmonary metastasis. MS is a rare variant of nerve sheath neoplasm of which less than 200 cases have been reported to date with three cases in Korean reports. ${ }^{2-5}$ MS can be divided into psammomatous and nonpsammomatous type, ${ }^{2}$ and approximately half of the psammomatous MS are related to Carney complex, an autosomal dominant disease with cardiac myxomas and Cushing syndrome. ${ }^{6}$ Nonpsammomatous MS is considered to be a sporadic type and commonly affects spinal nerves and paraspinal ganglia, whereas psammomatous type often involves autonomic nerves of viscera. In contrast to the typical encapsulation of conventional schwannoma, MS is a circumscribed but unencapsulated tumor, which may reflect the potential of more aggressive nature of MS such as an invasive growth pattern. In present study, the tumor showed infiltrative border that permeated the bone marrow space. Unlike the conventional schwannoma, which is a totally benign neoplasm, MS follows an unpredictable clinical course. Even devoid of overt histologic atypia, approximately $10 \%$ of MS follow a malignant course., Although MS could demonstrate nuclear pleomorphism and macronucleoli with expression of melanocytic markers, findings mimicking malignant melanoma, these histologic features are poorly correlated with the clinical outcome. However, unlike malignant melanoma which usually has frequent mitosis, MS has rare mitosis. In addition, histologic features of ample cytoplasm, cytoplasmic process, and indiscernable cell border as well as low proliferative index contribute to the diagnosis of MS rather than malignant melanoma. Presence of mitosis itself, particularly over one mitosis/ 10HPFs, is the only known risk factor of metastasis in MS. ${ }^{8}$ In present case, the tumor had histologic atypia —nuclear pleomorphism, prominent macronucleoli-and foci of necrosis which are worrisome histologic features in routine pathologic diagnosis. Moreover, more importantly, the mitotic count was up to $2 / 10 \mathrm{HPFs}$, which may have been a factor attributing to the lung metastasis.

Recently, Torres-Mora et al. ${ }^{8}$ carried out gene microarray study covering over 1,700 genes, showed different gene expression profile of MS from conventional schwannoma or malignant melanoma, and suggested that MS is a distinctive neoplasm, belonging neither to the conventional schwannoma nor malignant mel- 
anoma. Among pigmented lesions of central nervous system, MS lacks GNAQ codon 209 mutations, which is one of mutational descriptors found in leptomeningeal melanocytic lesions. ${ }^{9} \mathrm{Al}-$ though MS is a genetically interesting and ambiguous tumor, a genetic study of the present case was not available. Instead, immunohistochemical staining and electron microscopy helped to identify the abundant basal lamina and cytoplasmic melanosomes, which elucidated the features of both Schwann cell and melanocyte. Previous study described different basement membrane staining patterns of MS from conventional schwannoma and leptomeningeal melanocytic lesion. ${ }^{9}$ MS demonstrated pericellular staining of basement membrane on collagen type IV, similar to that of conventional schwannoma with or without a nesting pattern, whereas other melanocytic lesions had predominant nesting pattern.?

So far, only about 20 cases of metastatic MS have been reported, ${ }^{7,8010-16}$ which are shown in Table 1. This is the first metastatic and recurrent MS case in a Korean patient. The sporadic, spinal MS showed an aggressive biologic behavior-local recurrence and pulmonary metastasis - and the ancillary examination delineated the pericellular basal lamina and cytoplasmic melanosomes.

\section{Conflicts of Interest}

No potential conflict of interest relevant to this article was reported.

\section{Acknowledgments}

This study was supported by a faculty research grant of Yonsei University College of Medicine for 6-2015-0147.

The authors are deeply indebted to Dr. Yeon-Lim Suh in the Department of Pathology, Samsung Medical Center, for her insightful discussion that greatly improved the manuscript.

\section{REFERENCES}

1. Carney JA. Carney complex: the complex of myxomas, spotty pigmentation, endocrine overactivity, and schwannomas. Semin Dermatol 1995; 14: 90-8.

2. Louis DN, Ohgaki H, Wiestler OD, Cavenee WK. WHO classification of tumours of the central nervous system. Lyon: IARC Press; 2007.
3. Yim H, Go JH, Ahn CS, Hong SW, Jung WH. Pigmented (melanotic) schwannoma of the cervical spinal canal: a case report. Korean J Pathol 1995; 29: 256-62.

4. Yi S, Chin DK, Jin BH, Cho YE, Kim YS. Melanotic schwannoma in cervical spine: a case report. J Korean Neurosurg Soc 2001; 30: 916-20.

5. You SH, Suh YL, Kim JH. Melanotic acoustic schwannoma. J Korean Neurosurg Soc 2002; 31: 485-7.

6. Carney JA. Psammomatous melanotic schwannoma: a distinctive, heritable tumor with special associations, including cardiac myxoma and the Cushing syndrome. Am J Surg Pathol 1990; 14: 206-22.

7. Vallat-Decouvelaere AV, Wassef $\mathrm{M}$, Lot $\mathrm{G}$, et al. Spinal melanotic schwannoma: a tumour with poor prognosis. Histopathology 1999; 35: 558-66

8. Torres-Mora J, Dry S, Li X, Binder S, Amin M, Folpe AL. Malignant melanotic schwannian tumor: a clinicopathologic, immunohistochemical, and gene expression profiling study of 40 cases, with a proposal for the reclassification of "melanotic schwannoma". Am J Surg Pathol 2014; 38: 94-105.

9. Kusters-Vandevelde HV, van Engen-van Grunsven IA, Kusters B, et al. Improved discrimination of melanotic schwannoma from melanocytic lesions by combined morphological and GNAQ mutational analysis. Acta Neuropathol 2010; 120: 755-64.

10. Santaguida C, Sabbagh AJ, Guiot MC, Del Maestro RF. Aggressive intramedullary melanotic schwannoma: case report. Neurosurgery 2004; $55: 1430$

11. Tawk RG, Tan D, Mechtler L, Fenstermaker RA. Melanotic schwannoma with drop metastases to the caudal spine and high expression of CD117 (c-kit). J Neurooncol 2005; 71: 151-6.

12. Shields LB, Glassman SD, Raque GH, Shields CB. Malignant psammomatous melanotic schwannoma of the spine: a component of Carney complex. Surg Neurol Int 2011; 2: 136.

13. Faria MH, Doria-Netto RH, Osugue GJ, Queiroz Lde S, ChaddadNeto FE. Melanotic schwannoma of the cervical spine progressing with pulmonary metastasis: case report. Neurol Med Chir (Tokyo) 2013; 53: 712-6.

14. Khoo M, Pressney I, Hargunani R, Tirabosco R. Melanotic schwannoma: an 11-year case series. Skeletal Radiol 2016; 45: 29-34.

15. Rowlands D, Edwards C, Collins F. Malignant melanotic schwannoma of the bronchus. J Clin Pathol 1987; 40: 1449-55.

16. Killeen RM, Davy CL, Bauserman SC. Melanocytic schwannoma. Cancer 1988; 62: 174-83. 